\title{
The Effects of Lead Exposure on Serum Uric Acid and Hyperuricemia in Young Adult Workers: A Cross-sectional Controlled Study
}

\author{
Ali Erdem BAKİ, ${ }^{1}$ Timur EKİZ, ${ }^{2}$ Gökhan Tuna ÖZTÜRK, ${ }^{2}$ Engin TUTKUN, ${ }^{3}$ \\ Hınç YILMAZ, ${ }^{3}$ Mustafa Turgut YILDIZGÖREN ${ }^{1}$ \\ ${ }^{1}$ Department of Physical Medicine and Rehabilitation, Ankara Occupational Diseases Hospital, Ankara, Turkey \\ ${ }^{2}$ Department of Physical Medicine and Rehabilitation, Ankara Physical Medicine and Rehabilitation \\ Training and Research Hospital, Ankara, Turkey \\ ${ }^{3}$ Department of Toxicology, Ankara Occupational Diseases Hospital, Ankara, Turkey
}

\begin{abstract}
Objectives: This study aims to evaluate the relationship between serum uric acid levels and renal functions in asymptomatic subjects who had occupational lead exposure, particularly for shorter durations whereby saturnine gout has also been discussed.

Patients and methods: In this retrospective study, files of 100 males (mean age 34.5 \pm 5.9 years; range, 21 to 47 years) with occupational risk for lead exposure and 100 healthy male controls (mean age $34.47 \pm 5.8$ years; range 21 to 47 years) were reviewed. Demographic characteristics of the subjects and laboratory test results were recorded from the files. Creatinine clearance and 24-hour urinary creatinine were measured in the lead-exposed group.

Results: In the lead-exposed group, mean serum uric acid level was higher than those of the control group ( $p<0.001)$. Lead exposure time was negatively correlated with 24-hour urinary creatinine levels $(r=-0.373, p<0.001)$. In addition, serum uric acid levels were positively correlated with serum creatinine levels $(r=0.412, p<0.001)$ in the exposed group. Six patients had hyperuricemia (serum uric acid level $>6.8 \mathrm{mg} / \mathrm{dL}$ ) in the leadexposed group; however, all subjects' serum uric acid level was lower than $6.8 \mathrm{mg} / \mathrm{dL}$ in the control group ( $\mathrm{p}=0.029)$. Although 22 subjects had higher uric acid levels than $6.0 \mathrm{mg} / \mathrm{dL}$ in the lead-exposed group, only one control had higher uric acid level than $6.0 \mathrm{mg} / \mathrm{dL}(\mathrm{p}<0.001)$.

Conclusion: In light of our results, we may conclude that workers with lead exposure have higher frequency of hyperuricemia and higher serum uric acid levels than those of the control group. Therefore, we may imply that higher serum uric acid levels may be associated with renal impairment in lead-exposed subjects even in the earlier stages of exposure.

Keywords: Hyperuricemia; lead exposure; renal function; saturnine gout; uric acid.
\end{abstract}

Gout is a rheumatic disease related to hyperuricemia and caused by the deposition of monosodium urate crystals., ${ }^{1,2}$ On the other hand, saturnine gout is the rheumatic entity due to chronic lead toxicity. ${ }^{3}$ Previous studies have established that lead exposure causes renal dysfunction via direct tubular damage, tubulointerstitial fibrosis and increased reactive oxygen radicals. ${ }^{3-6}$ Hyperuricemia and secondary (saturnine) gout are common findings associated with chronic lead toxicity and they are thought to be due to isolated proximal tubular defects resulting in increased tubular reabsorption and decreased secretion of uric acid. ${ }^{7-9}$ Saturnine is originated from the word saturnus, the alchemist's term for lead, which was very cold like the planet Saturn. It was demonstrated that lead exposure positively correlated with uric acid levels in asymptomatic subjects with risk for occupational lead exposure. ${ }^{10}$ Furthermore, previous studies have shown that hyperuricemia might ensue due to lead intoxication ${ }^{2,11,12}$ eventually causing hypertension and kidney injury as well. ${ }^{11-15}$ However, the pertinent literature mainly comprises 
studies whereby the mean lead exposure time was longer than 10 years. ${ }^{10,15}$ Accordingly, in this study, we aimed to evaluate the relationship between serum uric acid levels and renal functions in asymptomatic subjects who had occupational lead exposure, particularly for shorter durations whereby saturnine gout has also been discussed.

\section{PATIENTS AND METHODS}

In this retrospective study, between January 2014 and July 2014 at the Ankara Occupational Diseases Hospital, files of 100 male adult workers (mean age $34.5 \pm 5.9$ years; range, 21 to 47 years) who had occupational lead exposure (blood lead levels higher than $10 \mu \mathrm{g} / \mathrm{dL}$ ) and a control group including 100 healthy males (mean age 34.47 \pm 5.8 years; range 21 to 47 years) were reviewed. The study protocol was approved by the local ethics committee. The study was conducted in accordance with the principles of the Declaration of Helsinki.

Inclusion criteria were to be aged between 20 and 50 years and having a history of $>1$ year employment in any of the following occupations; petrol attendants and petrol refinery workers, battery factory workers and wet cell battery chargers, car radiator repairers, painters and paint pigment workers and welders and corrosion pipe fitters. Subjects with hypertension, diabetes mellitus, previous renal disease, gout, presence of other systemic disease, and significant analgesic abuse were excluded.

Demographic characteristics of the subjects (including estimated duration of lead exposure) and laboratory test results [complete blood count, liver and renal (blood/urinary) function tests] were recorded from hospital database records. In addition, the data as regards the examination/ evaluation for gout such as arthritis, gout attacks, and joint swelling were noted.

Serum lead levels were established according to venous blood specimens. Ethylenediaminetetraacetic acid containing tubes were used for testing. Inductively coupled plasma mass spectrometry was used to determine blood lead levels. Blood lead levels higher than $10 \mu \mathrm{g} / \mathrm{dL}$ was accepted as occupational lead exposure. ${ }^{16}$ Additionally, creatinine clearance and 24-hour urinary creatinine were measured in workers with lead exposure. Creatinine clearance was calculated using the Cockcroft and Gault Formula ${ }^{17}$ as follows; Creatinine Clearance $=(140-$ Age years $) \times$ Body weight $\mathrm{kg} /$ Plasma Creatinine mg/dL x 72 .

\section{Statistical analysis}

Statistical analysis was performed by using SPSS for Windows version 16.0 software (SPSS Inc., Chicago, IL, USA). Data are expressed as mean \pm standard deviation. Student's t-test was used for comparisons between groups. Fisher's exact test was used to compare categorical variables. Correlations between subjects' characteristics were analyzed by using Pearson or Spearman correlation coefficients. Statistical significance was set at $p<0.05$.

\section{RESULTS}

The subjects were asymptomatic as regards hyperuricemia and their laboratory analyses are shown in Table 1. In the lead-exposed group, mean serum uric acid level was higher than those of the control group $(p<0.001)$. Lead exposure time was negatively correlated with 24-hour urinary creatinine levels $(r=-0.373$, $p<0.001$ ). In addition, serum uric acid levels were positively correlated with serum creatinine levels $(r=0.412, p<0.001)$ in the lead-exposed group.

Comparison of the groups according to the uric acid levels is shown in Table 2. Six patients had hyperuricemia (serum uric acid level $>6.8 \mathrm{mg} / \mathrm{dL}$ ) in the lead-exposed group; however, all subjects had uric acid levels lower than $6.8 \mathrm{mg} / \mathrm{dL}$ in the control group $(\mathrm{p}=0.029)$. Although uric acid level was higher than $6.0 \mathrm{mg} / \mathrm{dL}$ in 22 subjects in the lead-exposed group, it was higher than $6.0 \mathrm{mg} / \mathrm{dL}(\mathrm{p}<0.001)$ in only one subject in the control group.

\section{DISCUSSION}

In this study, we aimed to explore the possible relationship between lead toxicity and hyperuricemia in the young adult workers with lead exposure. Our results have shown that the 
Table 1. Laboratory test results of study subjects

\begin{tabular}{|c|c|c|c|}
\hline & Patients $(n=100)$ & Control $(n=100)$ & \\
\hline & Mean \pm SD & Mean \pm SD & $p$ \\
\hline Uric acid (mg/dL) & $5.2 \pm 1.0$ & $4.5 \pm 0.8$ & $<0.001$ \\
\hline Urea $(\mathrm{mg} / \mathrm{dL})$ & $13.0 \pm 3.7$ & $13.3 \pm 3.1$ & 0.565 \\
\hline Creatinine (mg/dL) & $0.9 \pm 0.1$ & $0.8 \pm 0.1$ & 0.247 \\
\hline Calcium (mg/dL) & $9.3 \pm 0.5$ & $9.3 \pm 0.4$ & 0.770 \\
\hline Phosphore (mg/dL) & $3.7 \pm 0.7$ & $4.0 \pm 0.9$ & 0.015 \\
\hline Alkaline phosphatase (U/L) & $204.3 \pm 49.4$ & $197.6 \pm 66.2$ & 0.445 \\
\hline Total protein (g/dL) & $7.0 \pm 0.5$ & $6.8 \pm 0.7$ & 0.020 \\
\hline Albumin $(\mathrm{g} / \mathrm{dL})$ & $4.3 \pm 0.3$ & $4.2 \pm 0.2$ & 0.042 \\
\hline Total bilirubin (mg/dL) & $0.8 \pm 0.4$ & $0.8 \pm 0.3$ & 0.386 \\
\hline Direct bilirubin (mg/dL) & $0.3 \pm 0.1$ & $0.3 \pm 0.1$ & 0.801 \\
\hline Aspartate aminotransferase (U/L) & $19.6 \pm 5.8$ & $21.0 \pm 7.4$ & 0.220 \\
\hline Alanin aminotransferase (U/L) & $22.4 \pm 13.5$ & $23.7 \pm 12.5$ & 0.436 \\
\hline Gamma-glutamyl transferase (U/L) & $30.9 \pm 17.8$ & $29.4 \pm 9.4$ & 0.924 \\
\hline 24-hour urine creatinine (mg/day) & $105.5 \pm 59.1$ & - & - \\
\hline Creatinine clearance (mL/min) & $127.1 \pm 42.6$ & - & - \\
\hline Duration of lead exposure (years) & $3.6 \pm 5.4$ & - & - \\
\hline Serum lead level ( $\mu \mathrm{g} / \mathrm{dL})$ & $24.3 \pm 11.6$ & - & - \\
\hline
\end{tabular}

frequency of hyperuricemia (6\% versus $0 \%$ ) and mean serum uric acid levels were increased in the exposed group when compared with the control subjects.

It has been previously reported that serum uric acid and urea levels were increased in the lead-exposed workers as compared to healthy controls. ${ }^{10,18-22}$ Additionally, it has been mentioned that serum creatinine levels were also higher in those subjects. In our study, although we have observed increased serum uric acid levels in the lead-exposed group; serum urea and creatinine levels were similar between the groups. As we have recruited subjects with shorter duration of lead exposure, we believe that our results are in conformity with the aforementioned studies..$^{10,18-22}$ Yet, hyperuricemia is expected to precede the possible secondary complications (increased creatinine/urea and saturnine gout) related with nephrotoxicity.

Although the creatinine levels were similar between the groups, serum uric acid level was positively correlated with serum creatinine in patients with lead exposure. Nonetheless, lead exposure time was negatively correlated with 24-hour urinary creatinine levels. Together with the absence of any correlation between creatinine clearance and uric acid levels, these findings may again be interpreted as early/mild renal function impairment. Likewise, previous studies have also reported that creatinine clearance was lower in lead-exposed workers ${ }^{23}$ and that it was negatively correlated with serum uric acid levels. ${ }^{15}$ This result also might be due to the shorter duration of lead exposure time in our study than the other studies. ${ }^{10,15,19-21}$ Alasia et al. $^{10}$ reported the mean duration of occupation in the study subjects as 11.9 years. Furthermore, Ehrlich et al. ${ }^{15}$ reported the mean exposure as 11.6 years. In our study, the mean duration of occupation was $3.6 \pm 5.4$ years.

There are mainly three distinct stages for gout as follows; asymptomatic hyperuricemia, acute intermittent gout, and advanced gout.

Table 2. Classification of groups according to serum uric acid levels

\begin{tabular}{lccr}
\hline Serum uric acid level & Patients $(\mathrm{n}=100)$ & & Controls $(\mathrm{n}=100)$ \\
\cline { 2 - 3 } & $\mathrm{n}$ & $\mathrm{n}$ & $p^{*}$ \\
\hline$>6.8 \mathrm{mg} / \mathrm{dL}$ & 6 & 0 & $\mathbf{0 . 0 2 9}$ \\
$>6.0 \mathrm{mg} / \mathrm{dL}$ & 51 & 1 & $<\mathbf{0 . 0 0 1}$ \\
$>5.0 \mathrm{mg} / \mathrm{dL}$ & 22 & 25 & $<\mathbf{0 . 0 0 1}$ \\
* According to Fisher's exact test; Bold values give the statistically significant results; Statistical \\
significance was set at $\mathrm{p}<0.05$.
\end{tabular}


Hyperuricemia refers to the plasma uric acid level higher than $6.8 \mathrm{mg} / \mathrm{dL} .{ }^{24}$ However, this range could be adapted according to the population. For instance, as for the chronic hyperuricemia and gout patients, serum uric acid level should be lower than $6.0 \mathrm{mg} / \mathrm{dL} .{ }^{24}$ Therefore, we have classified our subjects according to the uric acid levels. While six patients had greater uric acid levels than $6.8 \mathrm{mg} / \mathrm{dL}$ in the lead-exposed group, all subjects had lower uric acid levels than $6.8 \mathrm{mg} / \mathrm{dL}$ in the control group. Likewise, 22 subjects and only one subject had greater uric acid levels than $6.0 \mathrm{mg} / \mathrm{dL}$ in the lead-exposed and control groups, respectively.

Features of primary and saturnine gout differ from each other. Primary gout mainly affects males and postmenopausal females, in particular. However, saturnine gout has equal penetrance in both sexes. While primary gout presents with acute attacks, the frequency in saturnine gout is lower. The knee is the most commonly involved joint in saturnine gout whereas first metatarsophalangeal joint is the most commonly affected joint in primary gout. In addition, presence of chronic kidney disease, anemia, and proteinuria are more common in saturnine gout when compared with primary gout. ${ }^{3}$ In our study population, subjects were asymptomatic with relatively shorter lead exposure duration.

Our study has some limitations. First, measurement of blood lead levels shows recent exposure (six-week). Second, lead levels were not measured in the healthy subjects. However, control group did not yield a history of lead exposure. Third, our study population was not symptomatic. Last, our study sample was relatively small when compared with those of the previous studies.

In conclusion, hyperuricemia is more common and mean serum uric acid levels are higher in the lead-exposed workers (even in the earlier stages of exposure) when compared with the healthy subjects. Herein, we imply that rheumatologists should take into account occupational lead exposure for the differential diagnosis of hyperuricemia/gout. Keeping in mind the development of secondary (saturnine) gout and renal dysfunction, routine screening of relevant subjects as regards hyperuricemia should be considered. Last but not least, we herein once again highlight the preventive measures for chronic lead toxicity.

\section{Declaration of conflicting interests}

The authors declared no conflicts of interest with respect to the authorship and/or publication of this article.

\section{Funding}

The authors received no financial support for the research and/or authorship of this article.

\section{REFERENCES}

1. Yildizgören MT, Baki AE, Ekiz T. The sonographic appearance of podagra in gout. Arch Rheumatol 2014;29:236-7.

2. Asskın A, İnci R, Akan Ö, Demirdal S, Bayram K. A rare cause of knee pain in gout patients: Tophi of patella. Arch Rheumatol 2015;30:71-4.

3. Dalvi SR, Pillinger MH. Saturnine gout, redux: a review. Am J Med 2013;126:450.

4. Lin JL, Yu CC, Lin-Tan DT, Ho HH. Lead chelation therapy and urate excretion in patients with chronic renal diseases and gout. Kidney Int 2001;60:266-71.

5. Brewster UC, Perazella MA. A review of chronic lead intoxication: an unrecognized cause of chronic kidney disease. Am J Med Sci 2004;327:341-7.

6. Gonick HC, Ding Y, Bondy SC, Ni Z, Vaziri ND. Lead-induced hypertension: interplay of nitric oxide and reactive oxygen species. Hypertension 1997;30:1487-92.

7. Vaziri ND, Liang K, Ding Y. Increased nitric oxide inactivation by reactive oxygen species in lead-induced hypertension. Kidney Int 1999;56:1492-8.

8. Loghman-Adham M. Aminoaciduria and glycosuria following severe childhood lead poisoning. Pediatr Nephrol 1998;12:218-21.

9. Farkas WR, Stanawitz T. Effects of plumbous ion on guanine metabolism. $\mathrm{J}$ Inorg Biochem 1979;11:31-8.

10. Alasia DD, Emem-Chioma PC, Wokoma FS. Association of lead exposure, serum uric acid and parameters of renal function in Nigerian lead-exposed workers. Int J Occup Environ Med 2010;1:182-90.

11. Weaver VM, Jaar BG, Schwartz BS, Todd AC, Ahn KD, Lee SS, et al. Associations among lead dose biomarkers, uric acid, and renal function in Korean lead workers. Environ Health Perspect 2005;113:36-42.

12. Shadick NA, Kim R, Weiss S, Liang MH, Sparrow $\mathrm{D}, \mathrm{Hu} \mathrm{H}$. Effect of low level lead exposure on hyperuricemia and gout among middle aged and elderly men: the normative aging study. J Rheumatol 2000;27:1708-12. 
13. Johnson RJ, Kang DH, Feig D, Kivlighn S, Kanellis $\mathrm{J}$, Watanabe $\mathrm{S}$, et al. Is there a pathogenetic role for uric acid in hypertension and cardiovascular and renal disease? Hypertension 2003;41:1183-90.

14. Nawrot TS, Staessen JA. Low-level environmental exposure to lead unmasked as silent killer. Circulation 2006;114:1347-9.

15. Ehrlich R, Robins T, Jordaan E, Miller S, Mbuli S, Selby $\mathrm{P}$, et al. Lead absorption and renal dysfunction in a South African battery factory. Occup Environ Med 1998;55:453-60.

16. CDC. Adult Blood Lead Epidemiology and Surveillance (ABLES). Cincinnati, $\mathrm{OH}$ : US Department of Health and Human Services, CDC, National Institute for Occupational Safety and Health; 2013. Available at http://www.cdc.gov/ niosh/topics/ables/description.html.

17. Kasiske BL, Keane WF. Laboratory assessment of renal disease: Clearance, urinalysis, and renal biopsy. In: Brenner BM, Rector FC, editors. Brenner \& Rector's The Kidney. 6th ed. Philadelphia: WB Saunders; 2000. p. 1129-70.
18. Pinto de Almeida AR, Carvalho FM, Spinola AG, Rocha H. Renal dysfunction in Brazilian lead workers. Am J Nephrol 1987;7:455-8.

19. Ahmed K, Ayana G, Engidawork E. Lead exposure study among workers in lead acid battery repair units of transport service enterprises, Addis Ababa, Ethiopia: a cross-sectional study. J Occup Med Toxicol 2008;3:30.

20. Wang VS, Lee MT, Chiou JY, Guu CF, Wu CC, Wu TN, et al. Relationship between blood lead levels and renal function in lead battery workers. Int Arch Occup Environ Health 2002;75:569-75.

21. Jung KY, Lee SJ, Kim JY, Hong YS, Kim SR, Kim $\mathrm{DI}$, et al. Renal dysfunction indicators in lead exposed workers. J Occup Health 1998;40:103-9.

22. Endo G, Horiguchi S, Kiyota I. Urinary N-acetyl-betaD-glucosaminidase activity in lead-exposed workers. $\mathrm{J}$ Appl Toxicol 1990;10:235-8.

23. Pergande M, Jung K, Precht S, Fels LM, Herbort C, Stolte $\mathrm{H}$. Changed excretion of urinary proteins and enzymes by chronic exposure to lead. Nephrol Dial Transplant 1994;9:613-8.

24. Richette P, Bardin T. Gout. Lancet 2010;375:318-28. 